\title{
The Need for Human Resource Managers to Understand and Prepare for Future Employees: A Study on the Perceptions of Business Students on Job Performance
}

\author{
Belal A. Kaifi ${ }^{1}$, Nile M. Khanfar ${ }^{2}$, Wageeh A. Nafei ${ }^{3}$ \& Maryam M. Kaifi ${ }^{4}$ \\ ${ }^{1}$ College of Business Administration, Trident University International, USA \\ ${ }^{2}$ Nile M. Khanfar, College of Pharmacy_Palm Beach, Nova Southeastern University, USA \\ ${ }^{3}$ Menoufia University, Shebin El-Kom, Menoufia, Egypt \\ ${ }^{4}$ Los Medanos College, USA \\ Correspondence: Nile M. Khanfar, College of Pharmacy, Palm Beach, Nova Southeastern University, 11501 N. \\ Military Trail, Palm Beach Gardens, FL 33410, USA. Tel: 1-561-805-2242. E-mail: khanfar@nova.edu
}

$\begin{array}{ll}\text { Received: May 10, } 2013 & \text { Accepted: June 19, } 2013 \quad \text { Online Published: November 18, } 2013 \\ \text { doi:10.5539/jms.v3n4p103 } & \text { URL: http://dx.doi.org/10.5539/jms.v3n4p103 }\end{array}$

\begin{abstract}
Job performance is an important outcome of effective human resource management. This empirical research surveyed undergraduate students $(\mathrm{N}=176)$ majoring in Business Administration to learn more about their job performance propensities. A total of 88 male and 88 female students were surveyed. The results of this research suggest that females have higher citizen-based job performance levels when compared to males, males have higher task-based job performance levels when compared to females, males have higher outcome-based job performance levels when compared to females, and students who have played organized sports have a better understanding of job performance than students who have not played organized sports. Implications and recommendations are offered for practitioners and educators.
\end{abstract}

Keywords: job performance, business students, gender, sports, human resource management

\section{Introduction}

Job performance is formally defined as the set of employee behaviors that contribute to organizational goal accomplishment. Job performance is almost never one-dimensional. "What you measure is probably more critical to the control process than how you measure it" (Robbins \& DeCenzo, 2007, p. 156). As a practical example, a basketball player is assessed based upon his or her positive attributes in a number of different areas (e.g., points, assists, and rebounds per game). A basketball player is also assessed based upon his or her negative attributes in a number of different areas (e.g., personal fouls, technical fouls, and ejections). The different areas of a job that are usually assessed are also known as the job criteria. According to Mathis and Jackson (1994), "Each job criterion should be compared with a performance standard, which is the expected level of performance" (p. 327). With students graduating and entering the workforce, it is imperative for human resource managers to understand who to hire based upon certain job requirements that require different types of job performance propensities.

\section{Literature Review}

Job performance has three main categories (citizen-based, task-based, and outcome-based) and several sub-categories. A citizen-based criterion identifies subjective character traits such as being personable, caring, helpful, and courteous. A task-based criterion identifies the ability of an employee to complete tasks in an efficient, productive, and effective manner. Finally, an outcome-based criterion identifies the quality of the tasks that have been completed. All three complement one another and have been proven to be key areas of analysis and assessment for many employers. According to Lamberton and Minor (2010), "Experts are now becoming aware that the connections among job satisfaction and employee turnover, absenteeism, overall performance are not so simple" (pp. 90-91). It must be mentioned that employees who dominate in one area (but not the others) are usually considered "sub-optimal" employees. 
As HR managers plan for future hiring needs, it becomes imperative for them to consider who the best applicants are that will complement the organization. During the interview process, the interviewers should try to gauge how committed the employee will be because some researchers believe that there is a relationship between commitment and job performance. According to Becker et al. (1996), "it is possible that there is a relationship between commitment as a multidimensional phenomenon and performance" (p. 465). Applicants with higher levels of education, experience, and skills are more likely to have not only a competitive advantage but also a better understanding of the importance of job performance. Consequently, the human capital theory suggests that the abilities and knowledge acquired by individuals are likely to be rewarded with higher earnings in the labor market (Becker, 1964). Once an employee is hired, then it is imperative to manage the employee effectively. An HR manager will need to make sure that the employee is responsible for being productive and efficient. Figuring out the correct amount of tasks that need to be completed by each employee is a challenging endeavor for HR managers. According to Janssen (2001), "an increase in job demands is assumed to be beneficial for job performance and job satisfaction to, but not beyond, a certain level" (p. 1039). Furthermore, it should be mentioned that employees have different views on what they should be responsible for because employees usually have a number of tasks they enjoy completing on a daily basis and a number of tasks that they would rather not complete on a daily basis. This "selective" job performance dilemma causes chaos throughout organizations because certain tasks are not always completed up to par. Parker (2007) explains, "Even within the same job, employees will have different beliefs regarding what their role is about" (p. 404). This role ambiguity becomes an obstacle for the organization. Thus, HR managers should regularly remind employees of their important role in the organization and all of the important tasks that not be completed by each employee in order for the organization to be competitive and successful. Figure 1 illustrates the three broad criteria relevant to job performance.

\subsection{Job Performance Criteria}

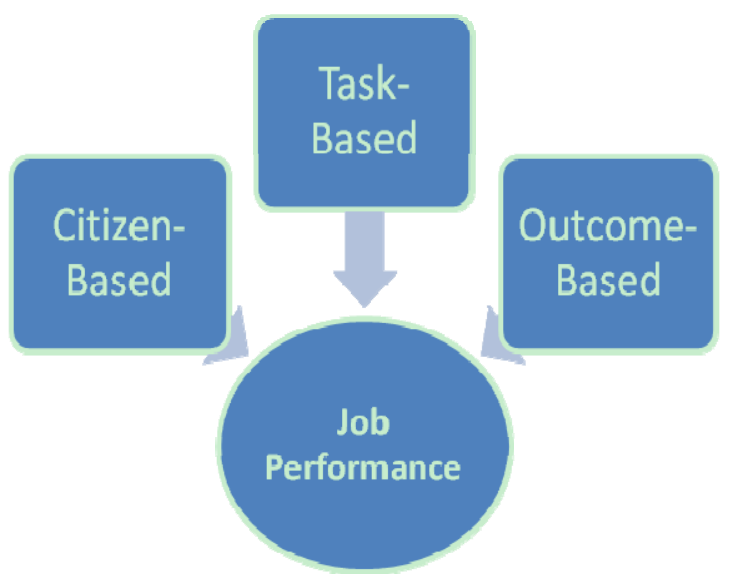

Figure 1. The three broad criteria relevant to job performance

The three broad criteria related to job performance underscore the importance of being a well-rounded employee (Kaifi, 2013). The following sections describe these criteria in greater detail.

\subsection{Citizen-Based Job Performance}

An employee's job performance can be assessed based upon his or her relationship with the entire organization. For example, organizations seek employees who will have a positive working relationship with colleagues, customers, and supervisors (also known as internal and external customers). If an employee is known for being dedicated and committed but is unable to get along with his or her peers, then the employee is considered to be more of a liability than an asset. The ideal employee will not only have a positive relationship with his or her peers, but will also promote a positive working relationship when he or she notices counterproductive behaviors. By the same token, organizations seek employees who will promote the organization in public and participate in voluntary meetings. The essence of being an "outstanding" employee has become the norm in many organizations. Most people would agree that employees who are considered to be "outstanding" or "valuable" have more job security and stability. At times, employees will go above and beyond what is expected of them to illustrate their citizenship behavior, which can be defined as voluntary employee activities that may or may not 
be rewarded and that contribute to the progression of the organization. Being a good citizen in a society (macro level) is similar to being a good citizen in an organization (micro level). Citizens of a society strive to be "outstanding" societal citizens by doing a little extra to help the society develop and citizens of an organization strive to be "outstanding" organizational citizens to help the organization progress.

\subsection{Task-Based Job Performance}

A job description will usually indicate the different tasks for which a potential employee will be responsible. Organizations are known to come up with job descriptions that provide a general standard for interested applicants. There are types of task performances: creative, adaptive, and routine.

Creative task performance is the degree to which employees develop and implement ideas that are both novel and useful. The reality is that creative task performance plays a larger role in all jobs. With globalization and competition, creative task performance will continue to play a major role in all jobs of the future. Adaptive task performance requires an employee to be able to "adapt and overcome" novel or unusual situations. All jobs have a component of adaptive task performance that can be extreme or insignificant. Routine task performance is associated with being responsible for the same task each day with very minimal variety or change.

\subsection{Outcome-Based Job Performance}

Outcome-based job performance evaluation is becoming more prevalent because of global competition. Employees can be great organizational citizens who complete all of their tasks in a timely manner; but what about the quality of their work, or the impact of their work on the organization, or the overall value of the employee to the organization? In one study, female supervisors seemed to focus more on the quality of work than their male counterparts did (Smayling \& Miller, 2012, p. 29). As a practical example, in education, teachers are evaluated based upon the "learning outcomes" of students. If a specific teacher's students are continuously able to perform well on standardized assessments, then the teacher will have more opportunities to teach. This same standard of evaluation of outcomes is also true for attorneys. For example, if a trial lawyer is able to produce exceptional "trial outcomes" by winning a lot of cases, he or she will have more clients and therefore more job security.

\section{Study Methodology}

A survey was distributed to 200 undergraduate students majoring in Business Administration in California. Of the 200 surveys that were distributed, 176 surveys were completed by 88 males and 88 females. This represents an $83 \%$ response rate. This small population sample can be used as a pilot study because of the convenience sampling method which cannot be generalized to all students who will be entering the workforce.

The research question for this study is: Is there a relationship between gender and higher job performance scores in regards to citizen-based job performance, tasked-based job performance, and outcome-based job performance? The research hypotheses for this study are as follows:

Hypothesis 1: Both male and female students will have the same scores as to citizen-based job performance.

Hypothesis 2: Both male and female students will have the same scores as to tasked-based job performance.

Hypothesis 3: Both male and female students will have the same scores as to outcome-based job performance.

Hypothesis 4: Students who have played organized sports will have higher overall job performance scores than students who have not played organized sports.

For the purpose of this study, job performance is defined as the value of the set of employee behaviors that contribute to organizational goal accomplishment.

\section{Study Results}

For each hypothesis an independent sample t-test was used to analyze the data. The following table represents the number of participants in this study based upon gender:

Table 1. Number of participants

\begin{tabular}{ll}
\hline Males & 88 \\
Females & 88 \\
$\mathrm{~N}=$ & 176 \\
\hline
\end{tabular}


H1: Both male and female students will have the same scores as to citizen-based job performance.

Table 2. Results: citizen-based job performance

\begin{tabular}{lll}
\hline & Male & Female \\
\hline Mean (Citizen-Based Job Performance) & 2.796 & 4.069 \\
Std. Deviation & 1.205 & .980 \\
\hline
\end{tabular}

Table 3. Two-tailed test

\begin{tabular}{ll}
\hline T-test & -7.686 \\
P-value (sig) & .000 \\
\hline
\end{tabular}

The first hypothesis, states that both male and female students will have the same scores as to citizen-based job performance ( $\mathrm{t}=-7.686, \mathrm{p}=.000)$. As shown in Table 2 , females have a significantly higher mean in citizen-based job performance than males.

H2: Both male and female students will have the same scores as to tasked-based job performance.

Table 4. Results: task-based job performance

\begin{tabular}{lll}
\hline & Male & Female \\
\hline Mean (Tasked-Based Job Performance) & 4.182 & 2.410 \\
Std. Deviation & .989 & .942 \\
\hline
\end{tabular}

Table 5. Two-tailed test

\begin{tabular}{ll}
\hline T-test & -7.686 \\
P-value (sig) & .000 \\
\hline
\end{tabular}

The second hypothesis, states that both male and female students will have the same scores as to tasked-based job performance $(\mathrm{t}=12.173, \mathrm{p}=.000)$. As shown in Table 4, males have a significantly higher mean in task-based job performance than females.

H3: Both male and female students will have the same scores as to outcome-based job performance.

Table 6. Results: outcome-based job performance

\begin{tabular}{lll}
\hline & Male & Female \\
\hline Mean (Outcome-Based Job Performance) & 3.580 & 2.681 \\
Std. Deviation & 1.396 & 1.140 \\
\hline
\end{tabular}

Table 7. Two-Tailed test

\begin{tabular}{ll}
\hline T-test & 4.673 \\
P-value (sig) & .000 \\
\hline
\end{tabular}

The third hypothesis, states that both male and female students will have the same scores as to outcome-based job performance $(\mathrm{t}=4.673, \mathrm{p}=.000)$. As shown in Table 6 , males have a significantly higher mean in outcome-based job performance than females.

Table 8 . Number of students

\begin{tabular}{ll}
\hline Students who have not played an organized sport & 101 \\
Students who have played an organized sport & 75 \\
$\mathrm{~N}=$ & 176 \\
\hline
\end{tabular}


H4: Students who have played organized sport will have a better understanding of job performance than students who have not played organized sports.

Table 9. Results: students who have/have not played organized sports

\begin{tabular}{lll}
\hline & Played an Organized Sport & Didn't play an Organized Sport \\
\hline Mean & 4.280 & 2.703 \\
Std. Deviation & .763 & 1.005 \\
\hline
\end{tabular}

Table 10. Two-tailed test

\begin{tabular}{ll}
\hline T-test & 11.828 \\
P-value (sig 2-tailed) & .000 \\
\hline
\end{tabular}

The fourth hypothesis, states that students who have played organized sports will have a better understanding of job performance than students who have not played organized sports $(\mathrm{t}=11.828, \mathrm{p}=.000)$. As shown in Table 9 , students who have played organized sports have a higher mean than those who have not. In this case, students who have played organized sports have a better understanding of job performance than students who have not played organized sports.

\section{Discussion, Implications and Limitations}

Job performance is an important issue when managing employees. As such, it becomes imperative for HR managers to consider and prepare for the new generation of workers who are entering the workforce. CEO's have attempted to formulate and implement strategies for maximizing job performance levels and have even banned telecommuting (e.g., Yahoo and Best Buy). Other organizations have implemented incentive programs and awards for employees with high levels of job performance. At Enterprise Rent-A-Car where employees work long hours, there are opportunities for performance-based bonuses that motivate employees to work a little harder and longer. Mary Kay is known for awarding its top sales representatives with a pink Cadillac. Interestingly enough, Chick-fil-A will give considerable gifts to store operators who are able to increase sales each year. Southwest employees with no absences or late arrivals over a three-month period receive two free airline tickets from the company. Employees can use these tickets any way they wish and can even give them away to a friend. At Starbucks, part-time baristas who work at least 20 hours a week receive full benefits. Moreover, some organizations are notorious for having restaurants, gyms, basketball courts, barber shops, and dry cleaning available on-site to enhance job performance levels and to make sure that employees stay at work for as long as possible.

This study set out to learn more about business students and their propensities regarding job performance. This study revealed that females have a significantly higher mean in citizen-based job performance than males. Women are passionate about collaboration and having input from the entire team. This should not be viewed as a person who is indecisive by management. This style of management leads to more creativity and stronger teams. Women are also more concerned with the wellbeing of others compared to men. Women as managers are more approachable; they do not mind questions, are organized, and more nurturing. These are all characteristics that make a good manager and leader and should not be overlooked (Parcheta, Kaifi, \& Khanfar, 2013, p. 244). Women are more concerned with interpersonal and organizational citizenship behaviors because they understand the positive implications it can have on the entire organization. Throughout history, women have faced a glass ceiling in organizations and may need to use their innate "motherly" instincts to help them progress in organizations. Women may have higher levels of citizen-based job performance when compared to men because men may be more involved with organizational politics and finding allies than focusing on the organization's goals and mission.

This study also revealed that males have a significantly higher mean in task-based job performance than females. Babcock (2008) explains, "Men are more likely than women to negotiate for resources, training, and other factors that boost job satisfaction and success" and further sates, "It stands to reason that men who seek out career opportunities will advance more quickly in their organizations than equally qualified women who do not (Babcock, 2008, p. 1). Some researchers believe that women are too conservative and are unable to improvise when needed. For example, Beckman and Menkhoff (2008) explain that, "Women are significantly more risk averse, tend to be less overconfident and behave less competitively oriented" (p. 379). Due to the fact that men are more willing to negotiate for what they need, they are more likely to complete tasks. This study also revealed 
that males have a significantly higher mean in outcome-based job performance than females. Overall men just ask for what they want with greater frequency than women (Babcock \& Laschever, 2003, p. 20). Men are concerned with the final outcome or the "bottom line" while women focus more on the entire process of a task. Interestingly enough, task-based job performance is becoming less important in today's workforce because the use of high-performing teams is becoming more imperative and being able to work effectively with your team will result in higher levels of task-based job performance. Thus, employers are less likely to hire individuals who merely have higher levels of task-based job performance and are more likely to hire individuals who are able to work collectively with others. Employees who have high levels of task performance and low levels of organizational commitment are considered lone wolves in the field of organizational behavior.

This study was able to reveal that students who have played organized sports have a higher overall job performance mean than those who have not. Playing sports enables an individual to be a part of a team and contribute to goal accomplishment. A team can be considered an organization. Those who have experience playing on a sports team have a better understanding of team dynamics, the importance of collaboration, unity, task performance, commitment, and rules and regulations. Moreover, being involved in teams can help an individual gain self-confidence and sense of comradery that will transfer over to the workforce. Those who have played sports are more likely to understand the importance of being punctual, accountable, and dependable. Therefore, HR managers should consider hiring graduates who have been involved in sports because they will have a better understanding of how an organization functions. For example, an individual who has grown up playing sports will have a better understanding of what the role of a leader is and how a leader can help motivate other individuals. HR managers can ask applicants whether or not they participated in any extracurricular activities while in school.

Finally, of the three major components of job performance, males scored higher on two out of the three. Some organizations may want to hire individuals who have higher citizen-based job performance scores while other organizations may be more concerned with outcome-based job performance or task-based job performance scores. Deciding who to hire is not an easy task and should be taken very seriously because the cost to replace an employee can be overwhelming. Furthermore, it is imperative to take into consideration that the employee should be a good "fit" for the organization and should complement the organization's culture. Moreover, it is imperative for managers to evaluate employees' job performance levels on a regular basis. This will provide managers with useful information that can be used strategically to help the organization progress.

There are several limitations to this study. First, a larger sample size may have yielded different results. Next, all of the students sampled in this study are Business Administration students and a more diverse pool of students (i.e., different majors such as Biology or Engineering) may have yielded different results. Consequently, additional information regarding time spent playing sports may have yielded interesting results. Future researchers should consider the above mentioned limitations when considering a similar study. In addition, future researchers should consider investigating the possible link between an individual's culture and job performance level. As such, a qualitative research study may yield useful results that can provide useful theory explaining why individuals have specific job performance levels and what influences those levels. Moreover, future researchers may want to survey respondents that are actually employed at the graduate level to derive a more valid conclusion. Over the past two decades, there has been very little research directly examining the relationship between educational levels and job performance (Ng \& Feldman, 2009, p. 89).

\section{Conclusion}

This study set out to learn more about job performance propensities and perceptions among undergraduate Business Administration students who will be entering the workforce. It is imperative to learn as much as possible about students who will be entering the competitive workforce because we live in a survival-of-the-fittest society that focuses on merit and where nepotism and favoritism are becoming extinct. By being able to learn more about job performances levels, HR Managers can do a more effective job of recruiting the best employees for their organization. Theoretically, it is important to understand how and why job performance levels can be enhanced. Practically, it is important for human resource managers to know what factors to look for when hiring employees for certain types of jobs. The research presented in this article suggests that of the three major components of job performance, males scored higher on two out of the three. Some organizations may want to hire individuals who have higher citizen-based job performance scores while other organizations may be more concerned with outcome-based job performance or task-based job performance scores. It all depends on the job and the expectations of the job. Furthermore, this research also yielded that playing sports is linked to higher levels of job performance and therefore is worthy of continued scholarly investigation. 


\section{References}

Babcock, L. (2008). What happens when women don't ask? Negotiation, 11(96), 1-4.

Babcock, L., \& Laschever, S. (2003). Women don't ask Negotiation and the gender divide. Princeton: Princeton University.

Becker, G. (1964). Human capital: A theoretical and empirical analysis with special reference to education. New York: Columbia University Press.

Becker, T., Billings, R., Eveleth, D., \& Gilbert, N. (1996). Foci and bases of employee commitment: Implications for job performance. Academy of Management Journal, 39(2), 464-482. http://dx.doi.org/10.2307/256788

Beckman, D., \& Menkhoff, L. (2008). Will women be women? Analyzing the gender difference among financial experts. Kyklos, 61(3), 364-384. http://dx.doi.org/10.1111/j.1467-6435.2008.00406.x

Coleman, V. I., \& Broman, W. C. (2000). Investigating the Underlying Structure of the Citizenship Performance Domain. Human Resource Management Review, 10, 25-44. http://dx.doi.org/10.1016/S1053-4822(99)00037-6

Janssen, O. (2001). Fairness perceptions as a moderator in the curvilinear relationships between job demands and job performance and job satisfaction. Academy of Management Journal, 44(5), 1039-1050. http://dx.doi.org/10.2307/3069447

Kaifi, B. A. (2013). Organizational Behavior: Managing and Leading Organizations. Tamarac, FL: Llumina Press.

Lamberton, L. H., \& Minor, L. (2010). Human Relations: Strategies for Success (4th ed.). Burr Ridge, IL: McGraw-Hill.

Mathis, R. L., \& Jackson, J. H. (1994). Human Resource Management (7th ed.). San Francisco, CA: West Publishing Corporation.

Ng, T., \& Feldman, D. (2009). How broadly does education contribute to job performance? Personnel Psychology, 62(1), 89-133. http://dx.doi.org/10.1111/j.1744-6570.2008.01130.x

Parcheta, N., Kaifi, B. A., \& Khanfar, N. (2013). Gender Inequality in the Workforce: A Human Resource Management Quandary. Journal of Business Studies Quarterly, 4(3), 240-248.

Parker, S. (2007). That is my job: How employees' role orientation affects their job performance. Human Relations, 60(3), 403-434. http://dx.doi.org/10.1177/0018726707076684

Robbins, S. P., \& DeCenzo, D. A. (2007). Supervision Today (5th ed.). Upper Saddle River, NJ: Pearson Prentice Hall.

Smayling, M., \& Miller, H. (2012). Job Satisfaction and Job Performance at the Internship Level. Journal of Leadership, Accountability, and Ethics, 9(1), 27-33.

\section{Copyrights}

Copyright for this article is retained by the author(s), with first publication rights granted to the journal.

This is an open-access article distributed under the terms and conditions of the Creative Commons Attribution license (http://creativecommons.org/licenses/by/3.0/). 